JGG 2021;69:250-254

doi: 10.36150/2499-6564-N452

\title{
Are visual disturbances (excluding diabetic retinopathy) more common in geriatric DM patients? Are they risks factor for the progression of disability?
}

\author{
Francesco Parmeggiani \\ Department of Translational Medicine and for Romagna, University of Ferrara, Ferrara, Italy
}

Received: July 30, 2021

Accepted: September 16, 2021

\section{Correspondence}

Francesco Parmeggiani

Department of Translational Medicine and for

Romagna, University of Ferrara, via Luigi Borsari 46, 44121 Ferrara, Italy

E-mail: francesco.parmeggiani@unife.it

How to cite this article: Parmeggiani $F$. Are visual disturbances (excluding diabetic retinopathy) more common in geriatric DM patients? Are they risks factor for the progression of disability? Journal of GerontologyandGeriatrics2021;69:250-254.https:// doi.org/10.36150/2499-6564-N452

(C) Copyright by Società Italiana

di Gerontologia e Geriatria (SIGG)

\section{(c) (i) () ()}

OPEN ACCESS

This is an open access article distributed in accordance with the CC-BY-NC-ND (Creative Commons Attribution-NonCommercial-NoDerivatives 4.0 International) license. The article can be used by giving appropriate credit and mentioning the license, but only for non-commercial purposes and only in the original version. For further information: https://creativecommons.org/licenses/by-nc-nd/4.0/deed.en

\section{RECOMMENDATIONS}

A. Geriatric DM patients should undergo regular, annual, comprehensive eye examinations to measure visual functioning and assess diabetic retinopathy and associated complications, as well as other frequent eye disorders (e.g., dry eyes, keratopathy, cataract, glaucoma, agerelated macular degeneration) for which both aging and DM are important risk factors.

B. Most geriatric DM patients have a high risk of cardiovascular and cerebrovascular thromboembolism. Thus, if a clinically significant diabetic macular edema is diagnosed in one or both eyes, the first recommended line of therapy is intravitreal administration of long-acting corticosteroid drugs.

C. More attention should be paid to vision rehabilitation programs that minimize the impact of visual loss on cognitive functioning and quality of life, which many visually impaired geriatric DM patients experience.

D. The management of DM patients can be improved through the use of multidisciplinary, multi-specialist care networks that systematically apply Artificial Intelligence (Al)-based procedures, especially for diabetic retinopathy screening and for developing treatment algorithms for diabetic macular edema.

\section{STRENGTH OF THE RECOMMENDATIONS}

The quality of the evidences is moderate to high. Recommendations are supported by published evidences and best practice (supported by expert opinion).

\section{SUPPORTING EVIDENCE}

See appendix.

\section{AREAS OF UNCERTAINTY AND FUTURE PERSPECTIVES}

Until now, the study of visual disturbances in patients with DM have mainly addressed the cause-and-effect relationships between the complications 
of diabetic retinopathy and the losses of best-corrected visual acuity (BCVA), but few data are available to draw attention on the other vision-threatening diabetic comorbidities among geriatric patients, as well as to better estimate their real-life vision abilities beyond BCVA. In geriatric DM patients with or without diabetic retinopathy, new investigations are warranted to understand whether vision decline is a result of ongoing neurodegeneration and its role in determining or exacerbating cognitive decline. Conventional tests are not wholly able to assess sight in its physiological complexity, especially considering some key visual functions which, similarly to BCVA, are closely related to vision-related quality of life, such as reading speed of continuous text and visual acuity in variable luminance setting. In the context of patient's empowerment aimed to improve the quality of ageing of people with chronic degenerative diseases, the methodological overcoming of "the traditional BCVA-based approach emphasizes the growing relevance of large-scale collection of poly-sensory real-world data. The innovative multifunctional tests for an enhanced vision's examination should be characterized by high levels of standardization and automation, minimum operator-patient interaction, easy and fast execution, low running costs, finally including a dataset arrangement predisposed to Al-based analyses.

\section{APPENDIX}

Loss of vision is a serious health problem among older people. In the general population of industrialized countries, about one third of people aged 65+ have some form of eye disease that compromises vision. The most common causes of sight loss in older people are cataract, age-related macular degeneration, glaucoma, and diabetic eye complications ${ }^{1,2}$.

There is a high prevalence of vision loss in geriatric DM patients, yet it continues to be under-diagnosed and under-treated ${ }^{3-5}$. Both cross-sectional and longitudinal studies have indicated that loss of vision is related to cognitive decline, and early interventions can minimize the clinical manifestations and progression of cognitive decline. Indeed, visual deterioration in older persons can be negatively associated with cognitive functioning, while maintaining good visual function can be an important intervention strategy to mitigate age-related cognitive and functional decline ${ }^{6-8}$.

There are several causes of impaired vision that arise from DM in geriatric patients, some directly due to changes in blood glucose concentration (hyperglycemia or hypoglycemia) that affect refraction by modifications in the shape and curvature of the crystalline lens, others secondary to eye pathologies such as complications related to diabetic retinopathy or different disorders, for which both aging and DM are important risk factors. DM in geriatric patients can be associated with dry eye syndrome, corneal diseases, cataract, glaucoma, age-related macular degeneration, retinal artery occlusion, retinal vein occlusion, and nonarteritic anterior ischemic optic neuropathy ${ }^{9-19}$.

On the other hand, as diabetes duration is one of the main risk factors for diabetic retinopathy, geriatric patients should be considered at high risk of developing DM-related retinal alterations that cause visual impairment, such as macular edema, vitreous hemorrhage, and retinal detachment, which can especially occur in poorly monitored patients ${ }^{20-22}$.

Diabetic macular edema is the main cause of irreversible central vision loss in DM patients. However, in recent years, the large-scale application of therapeutic protocols consisting of repeated intravitreal injections of corticosteroids and/or drugs acting against vascular endothelial growth factor (anti-VEGF) has replaced laser photocoagulation as the standard treatment for most patients with diabetic macular edema. In fact, these intravitreal treatments have been able to dramatically improve patients' visual prognosis, either by increasing their central vision or by preventing further visual loss. Repeated intravitreal administrations of long-acting corticosteroid drugs for treating geriatric patients with chronic diabetic macular edema should be recommended considering that i) the most common comorbidities for DM include microangiopathic disorders (retinopathy, neuropathy, and nephropathy) and macroangiopathic disorders (myocardial infarction, cerebrovascular stroke, and other severe thromboembolic events); ii) the latest guidelines suggest the use of corticosteroids and, in particular, dexamethasone implants, as first-line treatment in diabetic macular edema patients with high cardiovascular risk, and iii) there is insufficient evidence to definitively exclude an increased mortality risk or cardiovascular and cerebrovascular incidents among patients treated with anti-VEGF drugs because affected by diabetic macular edema ${ }^{23-31}$.

DM is associated with an increased risk of falls due to frailty. Together with aging, DM can significantly contribute to loss of vision and other sensory perceptions, becoming a critical factor for the management of geriatric patients during clinical practice, especially among those who also experience cognitive decline ${ }^{32,33}$. However, in many cases, early multidisciplinary care inclusive of personalized therapeutic and/or rehabilitation pathways can effectively address the patient's problem or prevent it from worsening.

In the case that a geriatric DM patient exhibits a visual disturbance despite having good levels of traditionally-measured BCVA, a more in-depth assessment 
should be carried out to assess contrast sensitivity, reading speed, post-glare and lowluminance BCVAs, but also considering that visual disturbances reported by the patient might be easily solved with lubricating eye drops or by prescribing new corrective glasses, for example. On the other hand, visual disturbances may also be due to diabetic retinopathy or to one of other eye diseases that are often misdiagnosed even if frequently associated with DM in geriatric patients ${ }^{34-36}$. In the short- to medium-period, the clinical management of geriatric DM can be improved by initiating multidisciplinary, multi-specialist care networks, in which ophthalmologists and orthoptist/ophthalmic assistant are involved to develop: i) tele-medicine procedures for the screening of diabetic retinopathy and other diabetes-related eye disorders using either conventional or innovative Al-based approaches ${ }^{37-39}$; ii) algorithms for personalized treatments of diabetic macular edema as well as other eye disorders frequently present in geriatric DM patients, analyzing their outcomes also using Al-equipped systems ${ }^{40-42}$; iii) multidisciplinary rehabilitation programs that can meet the needs of the visually impaired DM persons among geriatric population ${ }^{43-46}$.

\section{Ethical consideration}

None.

\section{Acknowledgement}

None.

\section{Funding}

This research received no external funding.

\section{Conflict of interest}

The Author declares no conflict of interest.

\section{Refecences}

1 Quillen DA. Common causes of vision loss in elderly patients. Am Fam Physician 1999;60:99-108.

2 Pelletier AL, Rojas-Roldan L, Coffin J. Vision loss in older adults. Am Fam Physician 2016;94:219-226.

3 Evans BJ, Rowlands G. Correctable visual impairment in older people: a major unmet need. Ophthalmic Physiol Opt 2004;24:161-180. https://doi. org/10.1111/j.1475-1313.2004.00197.x

4 Bowen M, Edgar DF, Hancock B, et al. The Prevalence of Visual Impairment in People with Dementia (the PrOVIDe study): a cross-sectional study of people aged 60-89 years with dementia and qualitative exploration of individual, carer and professional perspectives. Southampton (UK): NIHR Journals Library 2016;Jul. https://doi.org/10.3310/ hsdr04210
5 Chriqui E, Law C, Kergoat MJ, et al. Visual impairment in older institutionalised Canadian seniors with dementia. Ophthalmic Physiol Opt 2017;37:225-233. https://doi. org/10.1111/opo.12358

6 Mine M, Miyata K, Morikawa M, et al. Association of visual acuity and cognitive impairment in older individuals: Fujiwara-kyo Eye Study. Biores Open Access 2016;5:228234. https://doi.org/10.1089/biores.2016.0023

7 Zheng DD, Swenor BK, Christ SL, et al. Longitudinal associations between visual impairment and cognitive functioning: the Salisbury Eye Evaluation Study. JAMA Ophthalmol 2018;136:989-995. https://doi.org/10.1001/ jamaophthalmol.2018.2493

8 Swenor BK, Wang J, Varadaraj V, et al. Vision impairment and cognitive outcomes in older adults: the Health $\mathrm{ABC}$ Study. J Gerontol A Biol Sci Med Sci 2019;74:1454-1460. https://doi.org/10.1093/gerona/gly244

9 Markoulli M, Flanagan J, Tummanapalli SS, et al. The impact of diabetes on corneal nerve morphology and ocular surface integrity. Ocul Surf 2018;16:45-57. https://doi. org/10.1016/j.jtos.2017.10.006

10 Yoo TK, Oh E. Diabetes mellitus is associated with dry eye syndrome: a meta-analysis. Int Ophthalmol 2019;39:2611 . 2620. https://doi.org/10.1007/s10792-019-01110-y

11 Jan RL, Tai MC, $\mathrm{Ho} \mathrm{CH}$, et al. Risk of recurrent corneal erosion in patients with diabetes mellitus in Taiwan: a population-based cohort study. BMJ Open 2020;10:e035933. https://doi.org/10.1136/bmjopen-2019-035933

12 Chang YS, Tai MC, Ho CH, et al. Risk of corneal ulcer in patients with diabetes mellitus: a retrospective largescale cohort study. Sci Rep 2020;10:7388. https://doi. org/10.1038/s41598-020-64489-0

${ }^{13} \mathrm{Li} \mathrm{L}$, Wan XH, Zhao GH. Meta-analysis of the risk of cataract in type 2 diabetes. BMC Ophthalmol 2014;14:94. https://doi.org/10.1186/1471-2415-14-94

14 Drinkwater JJ, Davis WA, Davis TME. A systematic review of risk factors for cataract in type 2 diabetes. Diabetes Metab Res Rev 2019;35:e3073. https://doi.org/10.1002/ dmrr.3073

15 Zhao D, Cho J, Kim MH, et al. Diabetes, fasting glucose, and the risk of glaucoma: a meta-analysis. Ophthalmology 2015;122:72-78. https://doi.org/10.1016/j. ophtha.2014.07.051

${ }^{16}$ Chen X, Rong SS, Xu Q, et al. Diabetes mellitus and risk of age-related macular degeneration: a systematic review and meta-analysis. PLoS One 2014;9:e108196. https:// doi.org/10.1371/journal.pone.0108196

17 Chang YS, $\mathrm{Ho} \mathrm{CH}$, Chu CC, et al. Risk of retinal artery occlusion in patients with diabetes mellitus: a retrospective large-scale cohort study. PLoS One 2018;13:e0201627. https://doi.org/10.1371/journal.pone.0201627

18 Wang $\mathrm{Y}$, Wu S, Wen F, et al. Diabetes mellitus as a risk factor for retinal vein occlusion: a meta-analysis. Medicine (Baltimore) 2020;99:e19319. https://doi.org/10.1097/ md.0000000000019319 
19 Chen T, Song D, Shan G, et al. The association between diabetes mellitus and nonarteritic anterior ischemic optic neuropathy: a systematic review and meta-analysis. PLOS One 2013;8:e76653. https://doi.org/10.1371/journal. pone.0076653

20 Sinclair A, Saeedi P, Kaundal A, et al. Diabetes and global ageing among 65-99-year-old adults: findings from the International Diabetes Federation Diabetes Atlas, $9^{\text {th }}$ ed. Diabetes Res Clin Pract 2020;162:108078. https://doi. org/10.1016/j.diabres.2020.108078

${ }^{21}$ Larsen MB, Henriksen JE, Grauslund J, et al. Prevalence and risk factors for diabetic retinopathy in 17152 patients from the island of Funen, Denmark. Acta Ophthalmol 2017;95:778-786. https://doi.org/10.1111/aos.13449

22 Yusufu M, Zhang $X$, Sun $X$, et al. How to perform better intervention to prevent and control diabetic retinopathy among patients with type 2 diabetes: a metaanalysis of randomized controlled trials. Diabetes Res Clin Pract 2019;156:107834. https://doi.org/10.1016/j. diabres.2019.107834

${ }^{23}$ Haffner SM, Lehto S, Rönnemaa T, et al. Mortality from coronary heart disease in subjects with type 2 diabetes and in nondiabetic subjects with and without prior myocardial infarction. N Engl J Med 1998;339:229-234. https:// doi.org/10.1056/nejm199807233390404

24 Brun E, Nelson RG, Bennett PH, et al. Diabetes duration and cause-specific mortality in the Verona Diabetes Study. Diabetes Care 2000;23:1119-1123. https://doi. org/10.2337/diacare.23.8.1119

${ }^{25}$ Chen R, Ovbiagele B, Feng W. Diabetes and stroke: epidemiology, pathophysiology, pharmaceuticals and outcomes. Am J Med Sci 2016;351:380-386. https://doi. org/10.1016/j.amjms.2016.01.011

26 Avery RL, Gordon GM. Systemic safety of prolonged monthly anti-vascular endothelial growth factor therapy for diabetic macular edema: a systematic review and metaanalysis. JAMA Ophthalmol 2016;134:21-29. https://doi. org/10.1001/jamaophthalmol.2015.4070

27 Schmidt-Erfurth U, Garcia-Arumi J, Bandello F, et al. Guidelines for the management of diabetic macular edema by the European Society of Retina Specialists (EURETINA). Ophthalmologica 2017;237:185-222. https://doi. org/10.1159/000458539

28 Virgili G, Parravano M, Evans JR, et al. Anti-vascular endothelial growth factor for diabetic macular oedema: a network meta-analysis. Cochrane Database Syst Rev 2017;6:CD007419. https://doi.org/10.1002/14651858. cd007419.pub5

29 LeRoith D, Biessels GJ, Braithwaite SS, et al. Treatment of diabetes in older adults: an Endocrine Society Clinical Practice Guideline. J Clin Endocrinol Metab 2019;104:15201574. https://doi.org/10.1210/jc.2019-00198
30 Wang $\mathrm{H}, \mathrm{Ba} \mathrm{Y}$, Cai RC, et al. Association between diabetes mellitus and the risk for major cardiovascular outcomes and all-cause mortality in women compared with men: a meta-analysis of prospective cohort studies. BMJ Open 2019;9:e024935. https://doi.org/10.1136/ bmjopen-2018-024935

31 Figueras-Roca M, Figueroa MS, Calvo P, et al. Optimization of diabetic macular edema management in the realworld: a model of excellence in retina units. The EMUREX initiative. Ophthalmologica 2020;243:379-390. https://doi. org/10.1159/000506311

32 Vinik Al, Camacho P, Reddy S, et al. Aging, diabetes, and falls. Endocr Pract 2017;23:1117-1139. https://doi. org/10.4158/ep171794.ra

33 Hoogendijk EO, Afilalo J, Ensrud KE, et al. Frailty: implications for clinical practice and public health. Lancet 2019;394:1365-1375. https://doi.org/10.1016/ S0140-6736(19)31786-6

${ }_{34}$ Tsai LT, Liao KM, Jang Y, et al. Detecting visual function abnormality with a contrast-dependent visual test in patients with type 2 diabetes. PLoS One 2016;11:e0162383. https://doi.org/10.1371/journal.pone.0162383

35 Khan A, Petropoulos IN, Ponirakis G, et al. Visual complications in diabetes mellitus: beyond retinopathy. Diabet Med 2017;34:478-484. https://doi.org/10.1111/dme.13296

36 Ro-Mase T, Ishiko S, Omae T, et al. Association between alterations of the choriocapillaris microcirculation and visual function and cone photoreceptors in patients with diabetes. Invest Ophthalmol Vis Sci 2020;61:1. https://doi. org/10.1167/iovs.61.6.1

37 Boucher MC, Qian J, Brent MH, et al. Evidence-based Canadian guidelines for tele-retina screening for diabetic retinopathy: recommendations from the Canadian Retina Research Network (CR2N) Tele-Retina Steering Committee. Can J Ophthalmol 2020;55(1 Suppl 1):14-24. https:// doi.org/10.1016/j.jcjo.2020.01.001

38 Wang S, Zhang Y, Lei S, et al. Performance of deep neural network-based artificial intelligence method in diabetic retinopathy screening: a systematic review and meta-analysis of diagnostic test accuracy. Eur J Endocrinol 2020;183:41-49. https://doi.org/10.1530/eje-19-0968

39 Bhaskaranand M, Ramachandra C, Bhat S, et al. The value of automated diabetic retinopathy screening with the EyeArt system: a study of more than 100,000 consecutive encounters from people with diabetes. Diabetes Technol Ther 2019;21:635-643. https://doi.org/10.1089/ dia.2019.0164

40 Kodjikian L, Bellocq D, Bandello F, et al. First-line treatment algorithm and guidelines in center-involving diabetic macular edema. Eur J Ophthalmol 2019;29:573-584. https:// doi.org/10.1177/1120672119857511

41 Bandello F, Toni D, Porta M, et al. Diabetic retinopathy, diabetic macular edema, and cardiovascular risk: the importance of a long-term perspective and a multidisciplinary approach to optimal intravitreal therapy. Acta Diabetol 2020;57:513-526. https://doi.org/10.1007/ s00592-019-01453-z 
42 Rohowetz LJ, Sabates NR, Koulen P. Measuring anatomical outcomes of anti-vascular endothelial growth factor treatment of diabetic macular edema with artificial intelligence-a step toward individualized medicine. JAMA Ophthalmol 2020;138:953-954. https://doi.org/10.1001/ jamaophthalmol.2020.2464

43 Sloan FA, Yashkin AP, Chen Y. Gaps in receipt of regular eye examinations among medicare beneficiaries diagnosed with diabetes or chronic eye diseases. Ophthalmology 2014;121:2452-2460. https://doi.org/10.1016/j. ophtha.2014.07.020
44 Kaminsky TA, Mitchell PH, Thompson EA, et al. Supports and barriers as experienced by individuals with vision loss from diabetes. Disabil Rehabil 2014;36:487-496. https:// doi.org/10.3109/09638288.2013.800592

45 Jamous KF, Jalbert I, Kalloniatis M, et al. Australian optometric and ophthalmologic referral pathways for people with age-related macular degeneration, diabetic retinopathy and glaucoma. Clin Exp Optom 2014;97:248-255. https:// doi.org/10.1111/cxo.12119

46 SadeghpourN, AlishiriAA, Ajudani R, etal. Quantity and quality of vision using tinted filters in patients with low vision due to diabetic retinopathy. J Ophthalmic Vis Res 2015;10:429432. https://doi.org/10.4103/2008-322x.158893

\section{This statement is:}

Recommendation (supported by published evidence)

$\bowtie$ Best practice (supported by expert opinion)
Quality of the evidence (in the case of recommendation):

$\square$ Low

凶 Moderate

$\square$ High 